\title{
Double Cerclage in Cervical Insufficiency: A Single Tertiary Center Experience
}

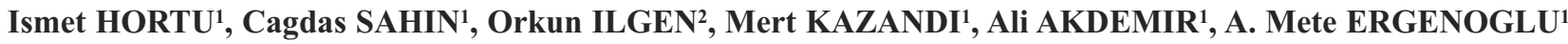 \\ Izmir, Turkey
}

\section{ABSTRACT}

OBJECTIVE: The aim of this study is to compare the perinatal outcomes of double cerclage via laparoscopic plus transvaginal technique in women with a history of transvaginal cerclage failure, between women with single transvaginal cerclage.

STUDY DESIGN: Five women who were diagnosed with cervical insufficiency with a history of at least one vaginal cerclage failure and 10 women who were diagnosed with cervical insufficiency were included in this study. Laparoscopic cerclage was performed to all women who have a medical history of vaginal cerclage failure, before pregnancy and additional transvaginal cervical cerclage was performed during their pregnancy (Group 1). Single transvaginal cervical cerclage was performed to the 10 women who had a short cervix and/or cervical insufficiency during their pregnancy (Group 2). The number of cerclage failure, perinatal outcomes, gestational week at the time of delivery, birth weight and Apgar scores were evaluated.

RESULTS: All five women in group 1 underwent a cesarean section. None of them had chorioamnionitis or poor obstetric outcomes and all gave birth after the $34^{\text {th }}$ week of pregnancy. All ten women in group 2 were evaluated. Two women gave birth vaginally at the $33^{\text {rd }}$ week of pregnancy. Remaining eight cases gave birth above $34^{\text {th }}$ week of pregnancy. Six of the eight cases underwent cesarean section and two of the remaining were delivered vaginally. Mean birth weight of the fetuses were $2490 \pm 265 \mathrm{~g}$ and 2.710 $\pm 361 \mathrm{~g}$ in group1 and group 2, respectively. Mean gestational age at the time of birth in group 1 and group 2 were found $36 \pm 1.83$ weeks and $35.6 \pm 1.14$ weeks, respectively.

CONCLUSION: Laparoscopic cervical cerclage during pregnancy could be a safe and effective treatment. However, sometimes it might not be enough and transvaginal cervical cerclage may be needed to strengthen cervical tension.

Keywords: Cervical insufficiency, Double cerclage, Laparoscopy

Gynecol Obstet Reprod Med 2020;26(2):70-74

\section{Introduction}

Cervical insufficiency is the dilatation of the incompetent cervix without pain or contraction and results in miscarriages

${ }^{I}$ Ege University School of Medicine Department of Obstetrics and Gynecology, Izmir, Turkey

${ }^{2}$ Dokuz Eylul University School of Medicine Department of Obstetrics and Gynecology, Izmir, Turkey

Address of Correspondence: Orkun Ilgen

Dokuz Eylul University School of Medicine

Department of Obstetrics and Gynecology,

35340 Izmir, Turkey

mdorkunilgen@gmail.com

Submitted for Publication:

16.04.2019

Accepted for Publication:

09.07 .2019

ORCID IDs of the authors:

CS: 0000-0001-7346-3987,

MK: 0000-0003-4317-066X

IH: 0000-0003-3833-0999,

OI: 0000-0002-0296-8504,

AA: 0000-0001-8723-5889, ME: 0000-0002-0811-3232

\begin{tabular}{|c|c|}
\hline Quick Response Code: & Access this article online \\
\cline { 2 - 2 } & Website: www.gorm.com.tr \\
& e- mail: info@gorm.com.tr \\
\cline { 2 - 3 } & DOI:10.21613/GORM.2019.953 \\
\hline
\end{tabular}

How to cite this article: Hortu I. Sahin C. Ilgen O. Kazandi M. Akdemir A. Ergenoglu AM. Double Cerclage in Cervical Insufficiency: A Single Tertiary Center Experience. Gynecol Obstet Reprod Med. 2020;26(2):70-74 and preterm delivery during the second trimester. Incidence of cervical insufficiency is $0.5 \%$ to $1 \%$ in all pregnancies. Significant symptoms are mostly the painless dilatation of the cervix and the pelvic pressure feeling especially in the second trimester of the pregnancy without rupture of membranes (1). Transabdominal cervical cerclage which is placed at the cervico-isthmic junction appears to be a safe and effective procedure to reduce the spontaneous miscarriages in selected patients with cervical insufficiency. Most of the time reasons to prefer the transabdominal way are anatomically distorted or shortened cervix by the procedures such as LEEP, conization of the cervix or obstetrical traumas. In addition, the other indication frequently seems to be failed transvaginal cerclage in the previous pregnancy.

Transvaginal cervical cerclage is a procedure that is the placement of the sutures circular around the cervix via transvaginal way. McDonald and Shirodkar techniques are being performed currently. Both techniques have fewer complications than the transabdominal way even when they are performed laparoscopically. The success of transabdominal cerclage in birth outcome may be due to the more proximal place- 
ment of the stitch (at the level of the internal os), decreased the risk of caudal suture migration as the uterus enlarges, and absence of a foreign body in the vagina that could provide reducing of infection and inflammation (2).

Cervical cerclage procedures could be performed in different ways and techniques via a transvaginal or laparoscopic way. Some studies supported the idea that double cerclage instead of one provides a better cervical competence to increase the gestational age on birth (3-5). Double cerclage is an alternative effective procedure to prevent poor perinatal outcomes. In a meta-analysis included 880 women, it is determined that double cervical cerclage is an effective way to reduce extreme preterm births and increase the gestational age on delivery, however it does not affect the antenatal morbidity and neonatal outcomes (3).

This article demonstrated our experience with the transvaginal cervical cerclage that strengthened cervix tension after laparoscopic placement of cervical cerclage (emergent cerclage) in five women all of whom had a history of failure single transvaginal cervical cerclage. In addition, we compared the perinatal outcomes of 10 women who have had only transvaginal cervical cerclage.

\section{Material and Method}

This retrospective study contains information between 2005-2017 in a university hospital. Five women who were diagnosed with cervical insufficiency was referred to our tertiary referral hospital. All five women had a history of at least one transvaginal cervical cerclage failure. Therefore, laparoscopic transabdominal cerclage prior to pregnancy and transvaginal cerclage were performed during pregnancy due to the short cervix and/or cervical dilation. Concerning all cases in the double cerclage group, second cerclage (vaginal) was an emergent operation, because of the cervical shortening and cervical opening. This might be attributed to the failure and/or inadequacy of the first abdominal cerclage.

Under general anesthesia, patients were placed in the dorsal lithotomy position, and a Foley catheter was inserted. Cohen cannula was inserted to the cervix to manipulate the uterus. Peritoneal cavity access was succeeded. Intraabdominal pressure was about $14 \mathrm{mmHg}$ during the procedure. Patients were placed in Trendelenburg position. A 10$\mathrm{mm}$ port was inserted through an umbilical incision. Ancillary 5-mm trocars were placed at the bilateral lower quadrant lateral area, the last $5 \mathrm{~mm}$ trocar placed in the upper left abdominal area. The vesicouterine peritoneum was dissected by the laparoscopic scissors and the bladder was detached from to expose the uterine isthmus and uterine vessels. The suture was done by the 5-mm mersilene tape at the level of the cervicoisthmic junction carefully to avoid uterine vessel injury. Intracorporeal knot tying was done. The procedure steps were shown in figure 1-3.

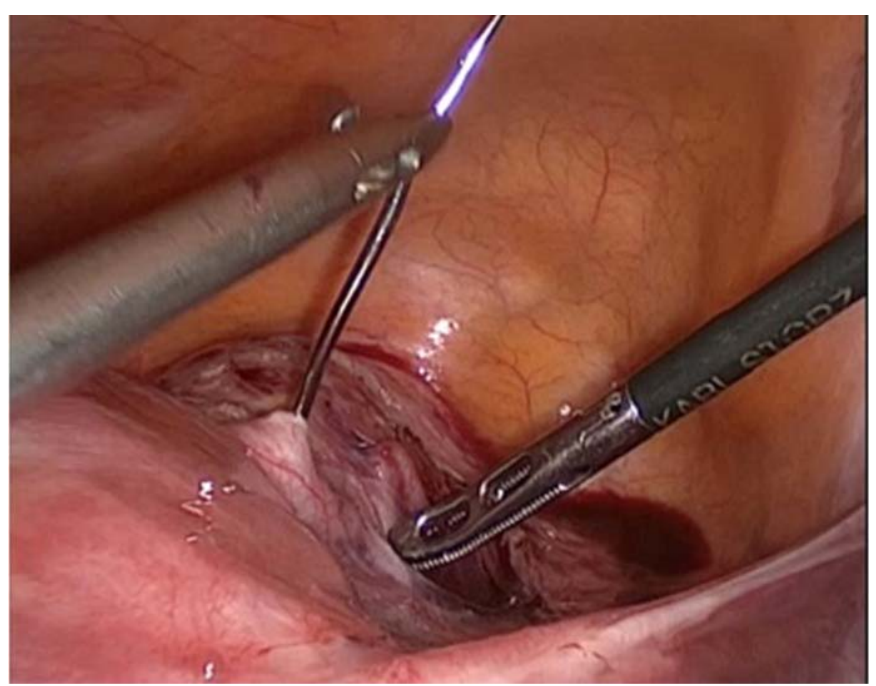

Figure 1: Needle insertion at the level of the isthmus region of the uterus

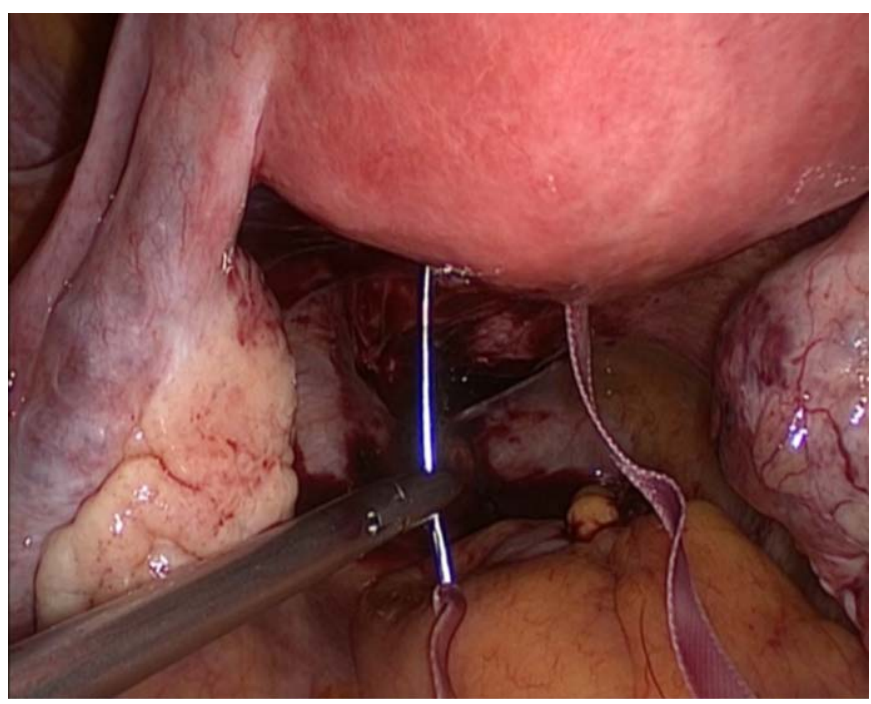

Figure 2: Mersilene-tape insertion at the posterior side of the isthmic uterus

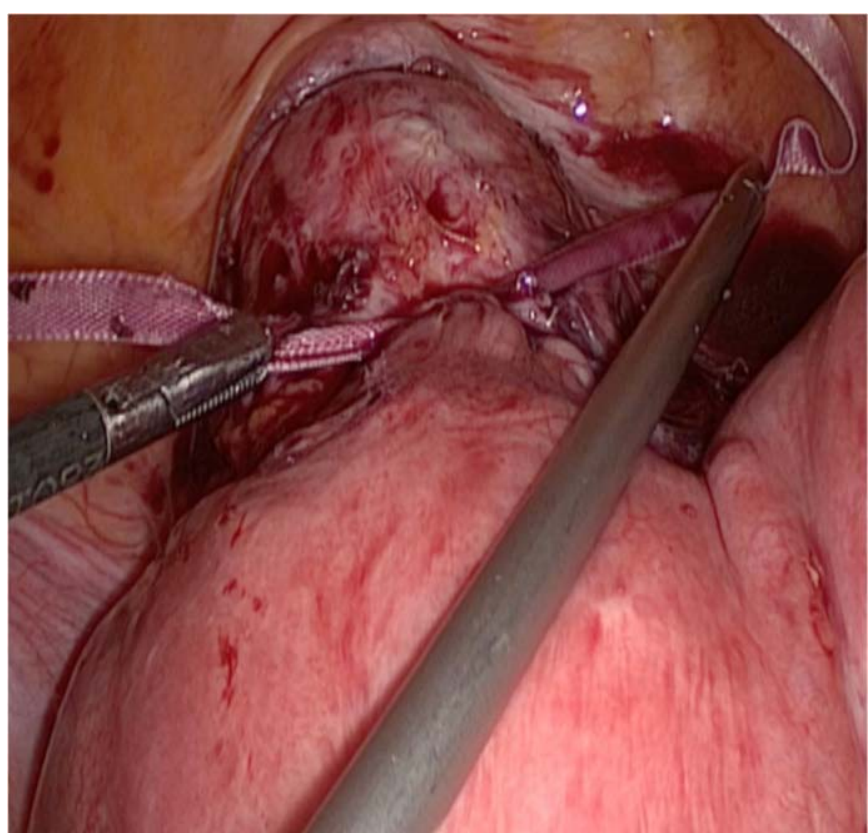

Figure 3: Knot tying at the end of the procedure 
Patients were evaluated at the end of first trimester or beginning of the second trimester of their pregnancies. Their 1sttrimester scan did not show any abnormal finding. Under these circumstances, vaginal examination and transvaginal ultrasonography were performed to the patients. On vaginal examination, mild cervical openness and short cervix were detected which is also confirmed with ultrasonography. Singleton pregnancy and fetal heart activity were seen on the patients. There was no contraindication to perform transvaginal cervical cerclage. Thereupon patients were informed and transvaginal cerclage was offered to strengthen cervix. Transvaginal McDonald type cerclage was performed. Perioperative prophylactic antibiotics were administered. Fetal cardiac activity was confirmed after the surgery. No tocolytic agents were needed except one dose of $500 \mathrm{mg}$-hydroxyprogesterone caproate. Cesarean section was scheduled for the patients. During cesarean section, the vaginal cerclage ligature was removed. On the other hand, 10 women who have only transvaginal cervical cerclage and history of second-trimester pregnancy loss because of cervical insufficiency were evaluated in view of perinatal outcomes. As inclusion criteria, the patients who were diagnosed with cervical incompetence were matched for such criteria as age, gravid, parity, and body mass index (BMI). Nevertheless, the patients who refused to participate in the study, or patients with Preterm Premature Rupture of Membranes (PPROM) or systemic or genital tract infection were excluded from the study. Consent for using data was obtained for this retrospective study. The study was conducted in accordance with the Declaration of Helsinki. Ethics committee approval was obtained.

\section{Statistical Analysis}

Statistical analyses were performed using the Statistical Package for the Social Sciences (SPSS, Inc., Chicago, IL,
USA), version 20.0. Student t-test was used to evaluate differences between groups. Results are presented as the mean \pm standard error of the mean or median (range). The $\mathrm{p}$ values $<$ 0.05 were considered as statistically significant.

\section{Results}

In this study, none of the patients in the group of double cerclage had antenatal morbidities such as chorioamnionitis or PPROM and all were given birth above $34^{\text {th }}$ week of pregnancy. Babies did not need care on neonatal intensive care unit (NICU) except one. Only one case had an intra-uterine fetal demise (IUFD) anamnesis in a prior pregnancy. A statistical significance was observed between single and double cerclage groups in terms of a number of second-trimester pregnancy loss; $1.5 \pm 0.71$ vs $2.8 \pm 0.45(p<0.05)$. All cases had mild cervical openness on vaginal examination and shortened cervical length confirmed by ultrasonography. The cervical length was significantly lower in the double cerclage group than in the single cerclage group; $17.2 \pm 1.3 \mathrm{~mm}$ and $27.4 \pm 2.8 \mathrm{~mm}$, respectively $(p<0.05)$. Apgar scores were positively correlated with gestational age at birth. Two women gave birth vaginally at the $33^{\text {rd }}$ week of pregnancy because of PPROM in the group of only-transvaginal cervical cerclage. Remaining eight cases were delivered above $34^{\text {th }}$ week of pregnancy. Six of the eight cases were undergone cesarean section and two of the remaining were delivered vaginally. Mean birth weight of the fetuses were $2710 \pm 361 \mathrm{~g}$ and $2490 \pm 265 \mathrm{~g}$ in single cerclage and in double cerclage groups, respectively. Moreover, the mean gestational age at the time of birth in single cerclage group and double cerclage group was found $36 \pm 1.83$-weeks and 35.6 \pm 1.14-weeks, respectively. Both groups (single and double cerclage) detailed perinatal outcomes and statistical data are given in table I.

Table I: Comparison between double cerclage and single cerclage groups

\begin{tabular}{|c|c|c|c|}
\hline & Single cerclage $(n=10)$ & Double cerclage $(n=5)$ & $p$ value \\
\hline Age (years) & $29.5 \pm 4.88$ & $33.2 \pm 2.48$ & 0.829 \\
\hline Gravida & $3.2 \pm 0.92$ & $4.4 \pm 1.14$ & 0.430 \\
\hline Parity (n, range) & $0.8(0-2)$ & $0.4(0-1)$ & 0.926 \\
\hline Miscarriages in second trimester & $1.5 \pm 0.71$ & $2.8 \pm 0.45$ & 0.036 \\
\hline History of IUFD ( $\mathrm{n}$, range) & 0 & $0.2(0-1)$ & 0.835 \\
\hline Prior cerclage failure & $1.4 \pm 0.70$ & $1.6 \pm 0.55$ & 0.995 \\
\hline Gestational age at cerclage (weeks) & $14.9 \pm 1.29$ & $14.8 \pm 1.92$ & 0.998 \\
\hline Cervical openness before cerclage $(\mathrm{cm})$ (range) & $0.9(0-2)$ & $2.4 \pm 0.89(1-3)$ & 0.053 \\
\hline Cervical length on sonography (mm) & $27.4 \pm 2.80$ & $17.2 \pm 1.30$ & $<0.001$ \\
\hline Antenatal morbidity ( $\mathrm{n}$, range) & $0.2(0-1)$ & 0 & 0.931 \\
\hline Neonatal morbidity ( $n$, range) & $0.2(0-1)$ & $0.2(0-1)$ & $>0.999$ \\
\hline Gestational age at birth (weeks) & $36 \pm 1.83$ & $35.6 \pm 1.14$ & 0.996 \\
\hline Weight of fetus (g) & $2710 \pm 361.94$ & $2490 \pm 265.52$ & 0.926 \\
\hline Apgar score $1^{\text {st }} \min$. & $6.7 \pm 1.06$ & $6.6 \pm 1.34$ & 0.998 \\
\hline Apgar score $5^{\text {th }} \min$. & $8.7 \pm 1.42$ & $9 \pm 1.41$ & 0.996 \\
\hline
\end{tabular}

IUFD: Intra-uterine fetal demise, Data are expressed as mean \pm standard error of the mean or median (range) 


\section{Discussion}

Women who have cervical insufficiency based on a dilated cervix on a digital or speculum examination at 16 to 23 weeks of pregnancy are potential candidates for a cerclage (6). In addition women with a singleton pregnancy, prior preterm birth, and a short cervical length $(<25 \mathrm{~mm})$ on transvaginal ultrasound examination at 16 to 23 weeks of gestation are potential candidates for a cerclage (7-9). A Cochrane review of studies of cerclage versus no cerclage in singleton pregnancies has shown that performing a cerclage may significantly decrease preterm birth under these circumstances (RR 0.80, 95\% CI 0.69-0.95; 9 trials, 2898 women) (10).

Conventional treatment of cervical insufficiency is thought to be transvaginal cerclage which is placed in the vaginal portion of the cervix in the subsequent pregnancy. The popular treatment of choice for the last 50 years has been cervical cerclage (11). Transvaginal cerclage was developed in 1955 and was associated with a significant failure rate in cases of anatomical distortion in the cervix.

First transabdominal cerclage was performed in 1965 as an alternative way to transvaginal cervical cerclage (12). Main reasons for preferring transabdominal cervico-isthmic cerclage in women with a short cervix of congenital origin or secondary to prior surgical procedures, and in those with severely lacerated cervix due to obstetric trauma. However, the main disadvantage is to need two laparotomies, one for cerclage and one for cesarean section. Hence, more surgery is associated with longer hospitalization and recovery (13). Laparoscopic surgical techniques are more preferred techniques in the last decades because of minimal invasiveness. Also, laparoscopy has better visualization and a magnified view of the operation area. This allows close approximation to the level of the internal cervical os during suturing laparoscopically. The procedure can be safely performed before pregnancy, avoiding the need for surgery during pregnancy like in our case (14). One of the complications of transvaginal cervical cerclage included chorioamnionitis is seen less in a laparoscopic procedure. Laparoscopic way also provides the benefits of decreased hospital stay and a faster recovery. With respect to the largest case report series of 20 patients who underwent transabdominal cerclage, the hospital stay ranged from 4 to 7 days (15). According to a study of 2007, 88 women delivered 96 pregnancies after transabdominal cerclage placement. The fetal salvage rate prior to transabdominal cerclage was $18 \%$, $93 \%$ after the procedure $(p<0.001)$. Delivery beyond 37 weeks occurred in $70 \%$ of pregnancies. It could be extracted from this passage that transabdominal cerclage is an option for women with a poor obstetric history including failed vaginal cerclage (16). In the present study, the cervical length was significantly lower in the double cerclage group than in the single cerclage group. There were no statistically significance regarding, mean birthweight of fetuses, Apgar scores, neonatal morbidity, and antenatal morbidity.
In our study, all five women in double cerclage group had at least one prior failed cerclage history and all of them were undergone a cesarean section. None of them had antenatal morbidities such as chorioamnionitis or PPROM and all were given birth above $34^{\text {th }}$ week of pregnancy. Babies were not admitted to the neonatal intensive care unit (NICU) except one. On the other hand, two women gave birth vaginally at the 33rd week of pregnancy because of PPROM in the group of onlytransvaginal cervical cerclage. Remaining eight cases gave birth after the $34^{\text {th }}$ week of pregnancy. Six of the eight cases underwent cesarean section and two of the remaining gave birth vaginally.

In conclusion, this study might indicate that transabdominal cerclage can sometimes be inadequate although it is safer. Hence, performing an additional transvaginal cervical cerclage would be beneficial for improving the cervical tensile power.

Acknowledgments: None

Conflict of interest: The authors declare no conflict of interest. Funding: None

Author contribution: IH: Interpreted the results and wrote the draft manuscript. Analyzed the data and reviewed the draft manuscript. CS: Interpreted the results and wrote the draft manuscript. OI: Interpreted the results and wrote the draft manuscript. Analyzed the data and reviewed the draft manuscript. MK: Conceived and designed the study. AA: Analyzed the data and reviewed the draft manuscript. AME: Conceived and designed the study.

\section{References}

1. Shennan A, Jones B. The cervix and prematurity: aetiology, prediction and prevention. Semin Fetal Neonatal Med. 2004;9(6):471-9.

2. Witt MU, Joy SD, Clark J, Herring A, Bowes WA, Thorp JM. Cervicoisthmic cerclage: transabdominal vs transvaginal approach. Am J Obstet Gynecol. 2009;201 (1):105.e1-4.

3. Pergialiotis V, Vlachos DG, Prodromidou A, Perrea D, Gkioka E, Vlachos GD. Double versus single cervical cerclage for the prevention of preterm births. J Matern Fetal Neonatal Med. 2015;28(4):379-85.

4. Zolghadri J, Younesi M, Asadi N, Khosravi D, Behdin S, Tavana Z, et al. Double versus single cervical cerclage for patients with recurrent pregnancy loss: a randomized clinical trial. J Obstet Gynaecol Res. 2014;40(2):375-80.

5. Tsai YL, Lin YH, Chong KM, Huang LW, Hwang JL, Seow KM. Effectiveness of double cervical cerclage in women with at least one previous pregnancy loss in the second trimester: a randomized controlled trial. J Obstet Gynaecol Res. 2009;35(4):666-71.

6. Ehsanipoor RM, Seligman NS, Saccone G, Szymanski LM, Wissinger C, Werner EF, et al. Physical examination- 
indicated cerclage: a systematic review and meta-analysis. Obstet Gynecol. 2015;126(1):125-35.

7. Berghella V, Odibo AO, To MS, Rust OA, Althuisius SM. Cerclage for short cervix on ultrasonography: meta-analysis of trials using individual patient-level data. Obstet Gynecol. 2005;106(1):181-9.

8. Owen J, Hankins G, Iams JD, Berghella V, Sheffield JS, Perez-Delboy A, et al. Multicenter randomized trial of cerclage for preterm birth prevention in high-risk women with shortened midtrimester cervical length. Am J Obstet Gynecol. 2009;201(4):375.e1--8.

9. Berghella V, Keeler SM, To MS, Althuisius SM, Rust OA. Effectiveness of cerclage according to severity of cervical length shortening: a meta-analysis. Ultrasound Obstet Gynecol. 2010;35(4):468-73.

10. Alfirevic Z, Stampalija T, Roberts D, Jorgensen AL. Cervical stitch (cerclage) for preventing preterm birth in singleton pregnancy. Cochrane Database Syst Rev. 2012;(6):CD008991.
11. Harger JH. Cerclage and cervical insufficiency: an evidence-based analysis. Obstet Gynecol. 2002;100(6): 1313-27.

12. Benson RC, Durfee RB. Transabdominal cervico uterine cerclage during pregnancy for the treatment of cervical incompetency. Obstet Gynecol. 1965;25:145-55.

13. Cho CH, Kim TH, Kwon SH, Kim JI, Yoon SD, Cha SD. Laparoscopic transabdominal cervicoisthmic cerclage during pregnancy. J Am Assoc Gynecol Laparosc. 2003; 10(3):363-6.

14. Liddell HS, Lo C. Laparoscopic cervical cerclage: a series in women with a history of second trimester miscarriage. J Minim Invasive Gynecol. 2008;15(3):342-5.

15. Novy MJ. Transabdominal cervicoisthmic cerclage: a reappraisal 25 years after its introduction. Am J Obstet Gynecol. 1991;164(6 Pt 1):1632-5.

16. Fick AL, Caughey AB, Parer JT. Transabdominal cerclage: can we predict who fails? J Matern Fetal Neonatal Med. 2007;20(1):63-7. 